\title{
The effects of acute magnesium supplementation on maximal intensity short-term exercise and subsequent effect on blood pressure and isokinetic knee extension during recovery
}

\author{
R. Pulford and L. Kass \\ University of Hertfordshire, Hatfield, Hertfordshire AL10 9AB, UK
}

$\mathrm{Mg}$ is an important mineral for $>300$ processes in the human body such as energy production, muscle anabolism and blood pressure regulation. However, there is limited research into $\mathrm{Mg}^{2+}$ performance-related effect on short-term high-intensity exercise and subsequent effect on blood pressure and muscle recovery post exercise. The aim of the present study was to investigate the effect of Mg supplementation on peak and mean power during all-out maximal-intensity short-term exercise in order to examine its effect on systolic (SBP) and diastolic blood pressure (DBP) post maximal exercise and to investigate whether muscular recovery, using post-exercise isokinetic knee extensions, could be improved.

Six healthy male subjects (mean age 20.8 years old, mean height $1.80 \mathrm{~m}$ and mean mass $79 \mathrm{~kg}$ ) were required to fill out a $3 \mathrm{~d}$ diet sheet before testing for analysis of $\mathrm{Mg}$ intake. The study was a double-blind repeated-measures cross-over design with subjects supplemented with either placebo (cornflour) or $300 \mathrm{mg}$ magnesium aspartate for $2 \mathrm{~d}$ before the test day and $300 \mathrm{mg}$ on the test day before testing. Maximal isokinetic extensions of five repetitions by the right leg were performed by each subject 1 week before the testing to produce a baseline result for peak torque $(\mathrm{N} / \mathrm{m})$. The test day consisted of subjects performing a $30 \mathrm{~s}$ Wingate anaerobic test (WAnT) ${ }^{(1)}$ and resting for $30 \mathrm{~min}$ post WAnT before performing five maximal isokinetic knee extensions at $60 \% \mathrm{~s}$ on the right leg. A further $100 \mathrm{mg}$ magnesium aspartate or placebo was given to each subject immediately post WAnT. Peak power and mean power (W) were recorded from each WAnT. Peak torque $(\mathrm{N} / \mathrm{m})$ was measured from the isokinetic knee extensions. SBP and DBP were recorded at rest and every 5 min during the 30 min recovery after the WAnT.

Mean peak power $(\mathrm{W})$ was significantly increased $(P<0.05)$ during the WAnT between the placebo condition $(851)$ and the $\mathrm{Mg}$ condition (912). Mean power (W) during the WAnT was also significantly increased (placebo 683, Mg 705; $P<0.05$ ). A significant increase $(P<0.05)$ was also found in mean peak torque $(\mathrm{N} / \mathrm{m})$ between the placebo condition $(196)$ and the Mg condition $(222)$. There was also a significant decrease $(P<0.05)$ in SBP during the $30 \mathrm{~min}$ post WAnT in the Mg condition $(120 \mathrm{mmHg})$ compared with the placebo condition $(125 \mathrm{mmHg})$, which represents a $5 \%$ lower mean SBP over the $30 \mathrm{~min}$. However, there was no significant difference $(P>0.05)$ in DBP between the placebo and the $\mathrm{Mg}$ condition during the $30 \mathrm{~min}$ recovery post WAnT.

These improvements in WAnT and peak torque may be a result of Mg acting as a 'second messenger' for insulin, thus increasing the insulin sensitivity of cell membranes ${ }^{(2)}$, allowing for a greater uptake of energy substrates such as creatine into the muscles ${ }^{(3)}$, a consequence of which would be an improved intramuscular recovery of phosphocreatine and ATP. It has been known for some time that intramuscular Mg elicits ATPase activity ${ }^{(4)}$ and that Mg-bound ATP present on the acto-myosin cross-bridges has been proved to speed up filament detachment ${ }^{(5)}$. This increased rate of ATP hydrolysis (from higher ATPase activity) on the myosin heads results in faster and stronger filament detachment and reattachment producing a faster and more powerful muscle contraction, as shown by the results of the present study. It is further suggested that the reduction in blood pressure can be attributed to increased vasodilation attributed to decreased $\mathrm{Ca}$ channel activity in the presence of $\mathrm{Mg}$, resulting in decreased vascular resistance ${ }^{(6)}$.

The present study demonstrates that Mg supplementation increases peak and mean power during a WAnT and can enhance recovery by reducing SBP and improving peak torque in an isokinetic knee extension after maximal short-term exercise. Further research on hypertensive recreational athletes is needed to build on these initial findings.

1. McArdle WD, Katch FI \& Katch VL (2006) Energy, Nutrition and Human Performance, 6th ed. Philadelphia, PA: Lippincott Williams and Wilkins.

2. Paolisso G, Scheen A, D'Onofrio F et al. (1990) Diabetologia 33, 511-514.

3. Burke L \& Deakin V (2006) Clinical Sports Nutrition, 3rd ed. Sydney, Australia: McGraw-Hill Pty Ltd.

4. Bárány M (1967) J Gen Phys 50, 197-218.

5. Gordon AM, Homsher E \& Ragnier M (2000) Phys Revs 80, 853-924

6. Altura BM, Altura BT, Carella A et al. (1987) Can J Phys Pharmacol 65, 729-745. 